\title{
Effects of ultrasound on the corneal endothelium: I. The acute lesion
}

\author{
LANCE E. OLSON, JOHN MARSHALL, NOEL S. C. RICE, AND \\ ROBERT ANDREWS
}

From the Departments of Clinical Ophthalmology and Visual Science, Institute of Ophthalmology, London

SUMMARY The ultrasonic radiation utilised in phacoemulsification procedures for the removal of cataractous lenses results in the widespread production of discrete lesions in the corneal endothelium. The morphology of this induced damage has been examined in rabbit and man using both scanning and transmission electron microscopy. The illustrated results are related to both the duration of the ultrasonic exposure and to the mechanisms of damage.

Phacoemulsification was introduced as a new technique for the surgical treatment of cataract by Kelman (1967). The principle of the technique is to fragment the lens nucleus by ultrasonic vibration, thereby allowing aspiration of the cataractous lens. The procedure is now used by many surgeons. The technique requires advanced microsurgical skills and there is a high incidence of complications during the period when a surgeon is inexperienced in the method (Cleasby et al., 1974; Hiles and Hurite, 1973). However, over a larger number of operations the complications are comparable to those with conrentional cataract procedures (Kelman, 1973).

Reports of the incidences of postoperative corneal oedema vary between zero (Kelman, 1974) and $18 \%$ (Cleasby et al., 1974). Recently endothelial cell destruction has been shown to occur during the phacoemulsification procedure (Polack and Sugar, 1976; Binder et al., 1976). These lesions have been attributed to a number of mechanisms which include the effects of irrigation, lens manipulation, and lens fragments in the anterior chamber, instrument contact with the endothelium, and ultrasound.

This paper investigates the effect of radiating ultrasound on corneal endothelium resulting from the application geometry and dosage commonly used during phacoemulsification.

\section{Materials and methods}

Adult Dutch rabbits weighing 2 to $3 \mathrm{~kg}$ were killed with intravenous pentobarbitone prior to enucleation. The pair of isolated eyes was transported to the

Address for reprints: Mr Noel S. C. Rice, FRCS, Moorfields Eye Hospital, City Road, London EC1V 2PD. phacoemulsifier in a constant temperature container maintained at room temperature. An average journey time was 45 minutes. On arrival the eyes were placed in a holder and a $3 \mathrm{~mm}$ incision was made at the limbus with the aid of a surgical microscope. The tip of a Cavitron-Kelman phacoemulsifier (Model 7007) was inserted into the anterior chamber parallel to the iris and at a depth approaching the edge of the pupil. Care was taken to avoid either the endothelium or lens capsule. The tip direction and location were noted and recorded. To one eye of each pair irrigation, aspiration, and ultrasound were given continuously for times ranging from 10 seconds to 5 minutes. Fresh glutathionebicarbonate-Ringer (GBR) solution maintained at room temperature was used for irrigation in all procedures. The ultrasonic transducer of the phacoemulsifier was fully tuned with a power setting of 8 . The other eye of each pair was used as a control and was therefore exposed only to irrigation and aspiration. In some control eyes air in comparable amounts to that sometimes seen clinically during the use of ultrasound was introduced and allowed to circulate in the anterior chamber.

In both experimental and control eyes after the removal of the phacoemulsifier tip cold fixative was immediately injected into the formed anterior chamber. After 5 minutes the cornea was excised at the limbus and placed into $50 \mathrm{ml}$ of fixative solution for 1 hour. The fixative consisted of $2.5 \%$ glutaraldehyde buffered in $0 \cdot 1 \mathrm{M}$ sodium cacodylate containing $10 \mathrm{mg} / \mathrm{ml}$ calcium chloride with a final $\mathrm{pH}$ of $7 \cdot 4$. After a brief wash in sodium cacodylate buffer containing $7.5 \%$ sucrose the corneas were postfixed in $2 \%$ osmium tetroxide for 1 hour, dehydrated through a graded series of ethanol concentrations in water, 
and embedded in Epon via epoxypropane. In the uncured Epon each cornea was hemisected and half was prepared for scanning electron microscopy (SEM) by the method of Cleveland and Schneider (1969) and half for transmission electron microscopy (TEM).

In a second series of experiments paired human donor eyes were removed within 3 hours of death and used during the following hour. The experimental procedure and controls were exactly as described above. Several experimental eyes were observed and photographed by specular microscopy before fixation.

\section{Results}

In all samples surveyed by specular microscopy endothelial lesions were seen randomly distributed over the entire cornea but with a greater frequency in the central $5 \mathrm{~mm}$. Changing the direction or position of the ultrasound tip did not alter this distribution.

\section{SCANNING ELECTRON MICROSCOPY}

Cell destruction and loss were observed in all experimental corneas studied. The earliest lesions seen in rabbit corneas appeared after 10 seconds of ultrasound. In both rabbit and man these earliest changes involved single cells and showed as disruption of the cellular membrane together with a widening of the intercellular space. Thus damaged cells appeared shrunken and isolated from apparently normal adjacent cells (Fig. 1). With increasing damage the cells appeared condensed, and in consequence their nuclei protruded into the anterior chamber (Fig. 1, 2a). In severe lesions cells were either shed from Descemet's membrane (Fig. $2 b$ ) or the condensed appearance spread to involve contigous cells (Fig. 3). Where cells were lost, those adjacent to the area of damage immediately extended pseudopodia-like processes along Descemet's membrane into the denuded region (Fig. $2 b$ ).

With increasing exposure times the lesions enlarged in a centrifugal manner to involve adjacent cells. In some cases the coalescence of 2 or more enlarged lesions resulted in the creation of huge endothelial defects.

An exposure of 2 minutes of ultrasound created lesions in all stages of development, ranging from defects in individual cells to defects 20 to 30 cells in diameter (Fig. 4). In some of the larger lesions produced by this exposure duration there was evidence that the endothelium around the edges of the lesion had separated from Descemet's membrane and was protruding into the aqueous. After 5 minutes of ultrasound many amoeba shaped lesions were observed, and most now had such sheets of endothe- lial cells protruding into the anterior chamber (Fig. 4b).

Human corneas examined after 2 minutes of ultrasound showed lesions in various stages of development and similar to those seen in rabbits, with minor differences. The nuclei were rounded, more uniform, and much more prominent in the condensed cell stage. In areas of cell loss Descemet's membrane was overlaid by membranous debris (Fig. 2b) A 5-minute exposure to ultrasound caused less extensive endothelial damage in human eyes than that observed in rabbits.

Human corneas with advanced Fuchs's endothelial dystrophy (Fig. 5) had random endothelial lesions after ultrasound with a morphology similar to those produced in normal human corneas. However, when individual lesions included a guttata, the cell loss appeared to originate over and around the excrescence on Descemet's membrane.

TRANSMISSION ELECTRON MICROSCOPY

The range of ultrasonically induced endothelial lesions described above could be clearly determined in sections prepared for light microscopy. In addition, in all experimental samples anomalously stained areas were observed which were not associated with changes in surface topography. In the transmission electron microscope these pale staining areas are seen as regions of cytoplasmic disruption adjacent to Descemet's membrane (Fig. 6a). The cell membranes in these areas appeared unaffected, and there was no evidence of disruption of organelles. However, with increasing disruption first the Golgi bodies became swollen and vacuolated, and then ribosomes were lost. No significant changes were seen in the mitochondria.

In many cells with severe cytoplasmic disruption the nuclei assumed a rounded conformation and the surface membrane collapsed towards Descemet's. These changes were observed in both isolated single cells, and in lesions involving several cells, and correspond to the condensed cells with nuclear protrusions seen in SEM preparations.

Primary areas of cell loss were seen to arise from a rupture of the apical membrane, as in almost all lesions remnants of the shed cell's membrane could be seen in association with both Descemet's membrane and those of adjacent cells. In both rabbit and human samples extra-cellular mitochondria and nuclei were often observed in conjunction with these membrane remnants, but nuclear retention was far more common in the human (Fig. 6b). Damage to Descemet's membrane was rare and consisted of a fragmentary loss of fibrous material from the endothelial side. This was observed only in a few of the largest lesions. 

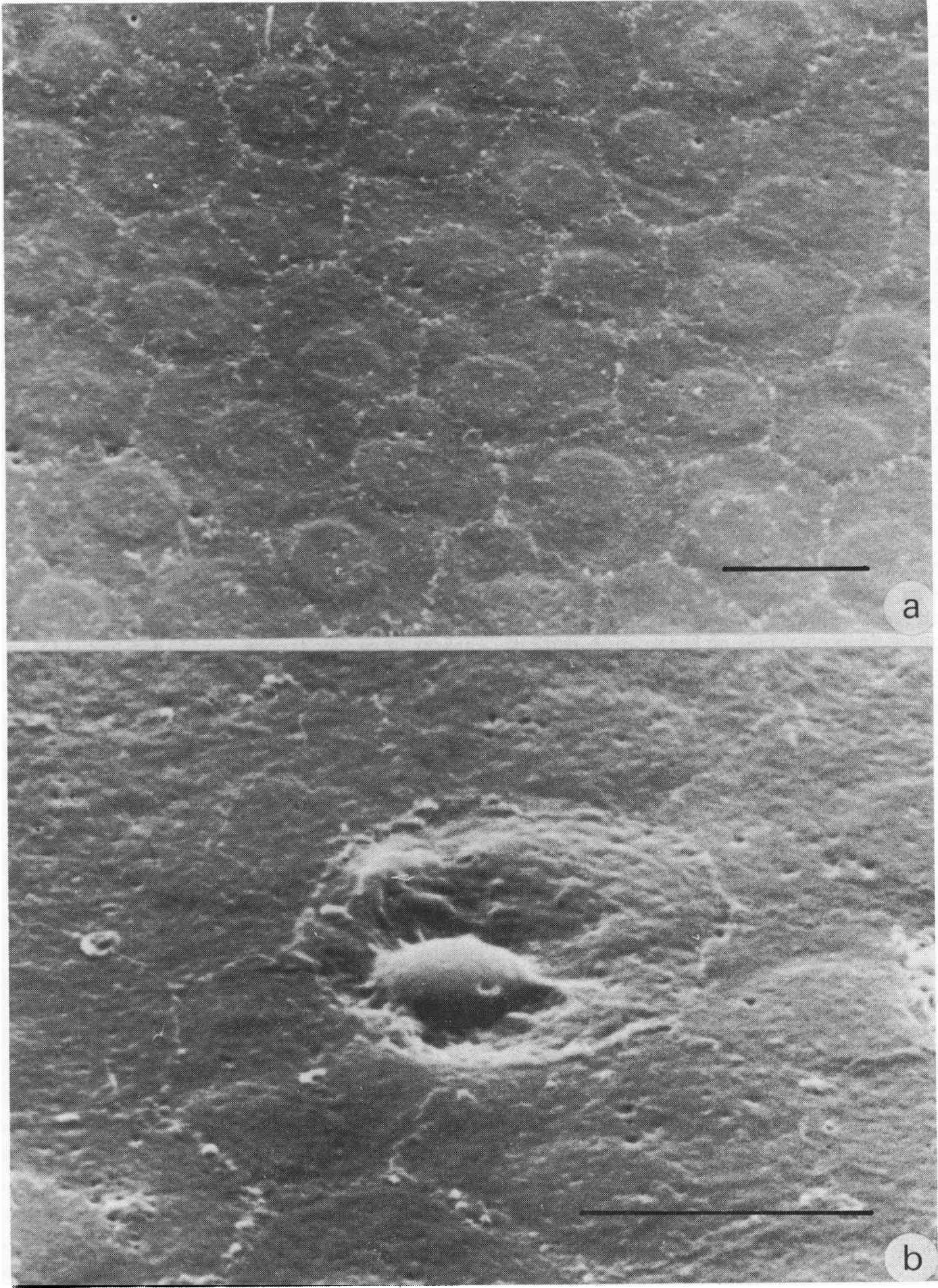

Fig. 1 Scanning electron micrographs of human corneal endothelium. (a) Normal endothelium. (b) Mild damage in a single cell after a 5-minute exposure to ultrasound. The nucleus is prominent in the damaged cell due to the collapse of the apical membrane. Bar markers: $a=20 \mu \mathrm{m}, b=20 \mu \mathrm{m}$ 

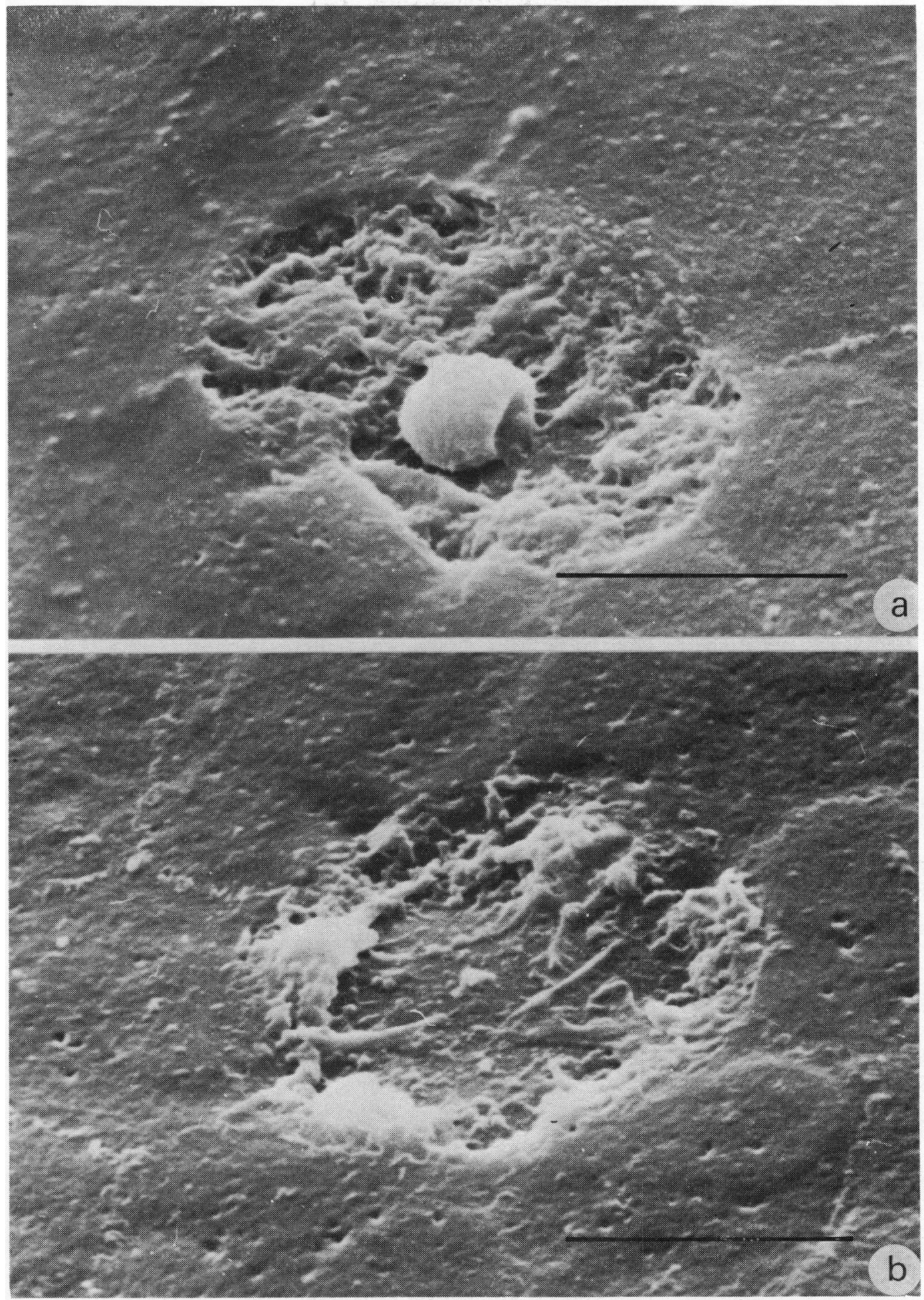

Fig. 2 Scanning electron micrographs of single cell lesions of increasing severity, in human endothelium, resulting from a 5-minute exposure to ultrasound. In both lesions the area of damage is apparently larger than a single cell, but the increase arises through a process of withdrawal of adjacent cells. (a) A single cell lesion showing the presence of debris on Descemet's membrane and the nuclear retention common in such lesions in human material. (b) A single cell lesion showing reduced amounts of debris and the loss of its nucleus. Bar markers: $a=20 \mu \mathrm{m}, \mathrm{b}=20 \mu \mathrm{m}$ 

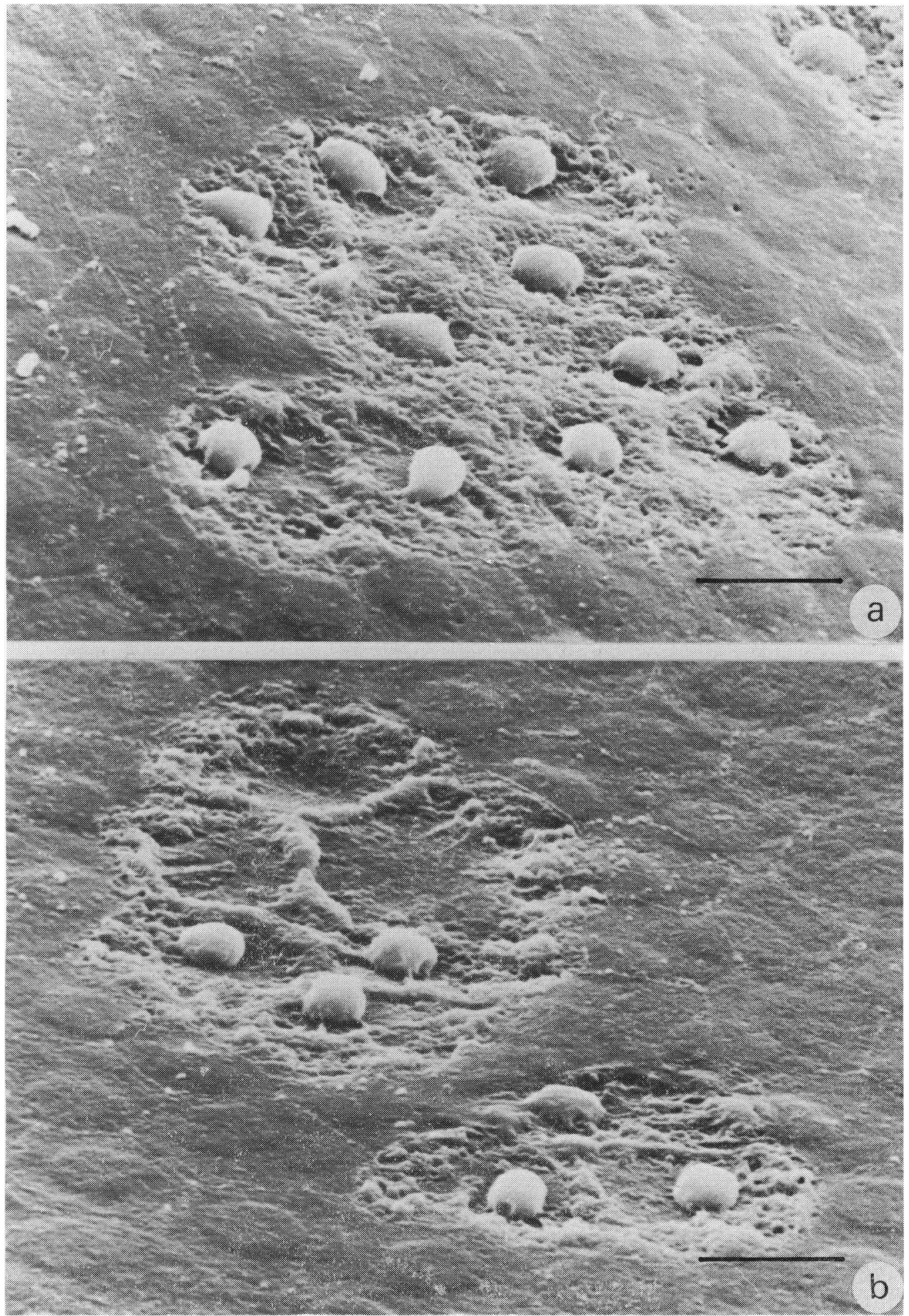

Fig. 3 Scanning electron micrographs of human corneal endothelium after 5 minutes' exposure to ultrasound. These micrographs show lesions involving several cells damaged to varying degrees. Bar markers: $a=20 \mu \mathrm{m}, b=20 \mu \mathrm{m}$ 

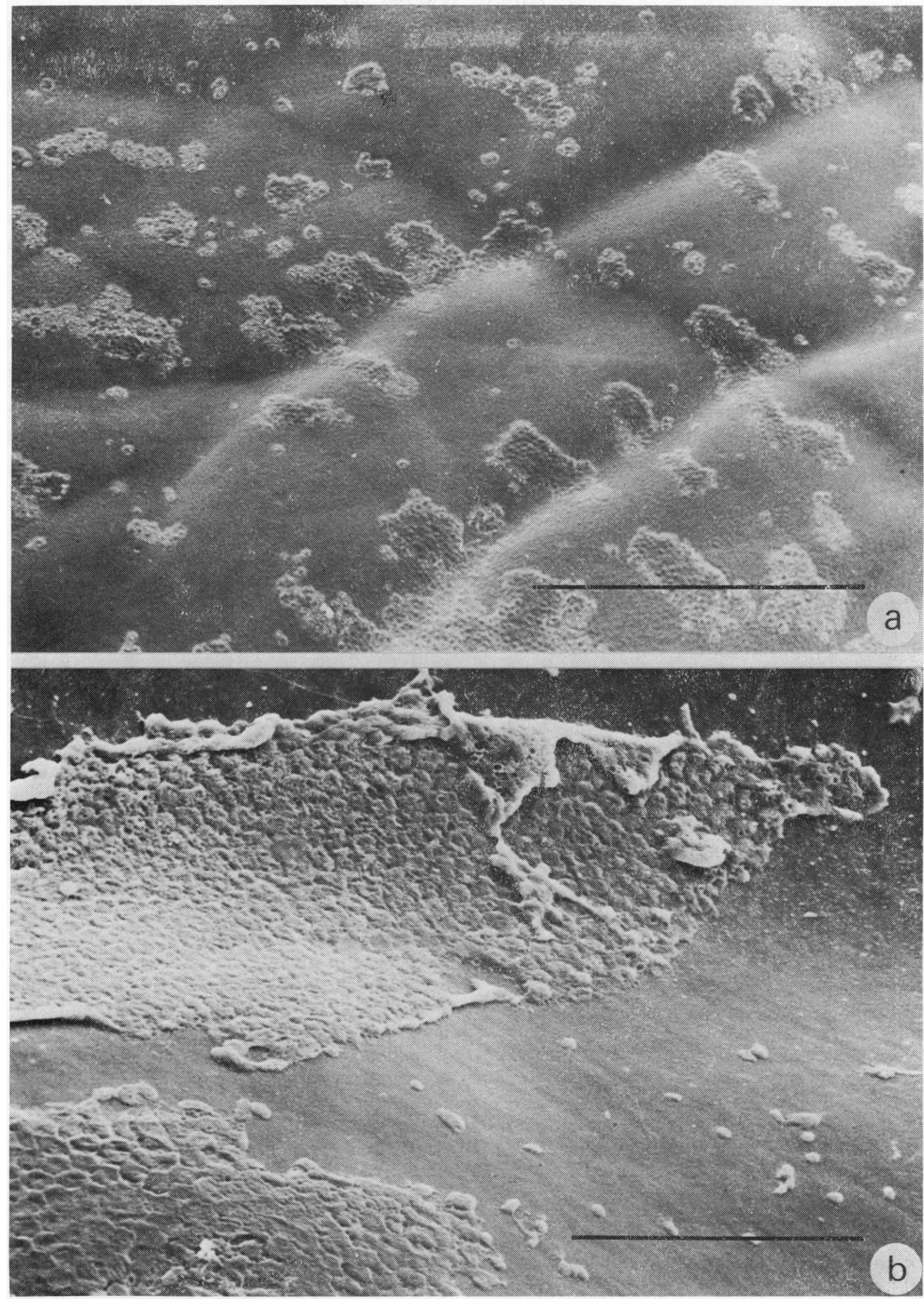

Fig. 4 Scanning electron micrographs of rabbit corneal endothelium after a 2-minute exposure. (a) The number and distribution of ultrasonically induced lesions are clearly apparent. The folds in this preparation are an artefact induced by the processing technique. (b) An area showing sloughing of the endothelial layer and the protrusion of a free edge into the anterior chamber. Bar markers: $a=1 \mathrm{~mm}, \mathrm{~b}=200 \mu \mathrm{m}$ 
The changes in cells adjacent to lesions were related to the size of the lesion. In small lesions involving either condensation or loss of 1 or 2 cells, the adjacent cells had long tapering pseudopodialike extensions which made incursions into the periphery of the damaged region (Fig. 7). Thus in all small lesions in which cells were lost a shallow pit with inclined walls resulted. The pseudopodia were devoid of organelles except at their thickest portion where they were confluent with the cell body.

In larger lesions cytoplasmic disruption was often seen in the cells around the periphery, and pseudopodia if present were short and extremely thin. In lesions previously described (SEM) which had a protrusion of endothelial cells into the anterior chamber the protruding cells had disrupted cytoplasm, but the apical membranes were always intact, and remnants of the basal membrane were always found on Descemet's.

None of the above changes were observed in control tissue which had merely been subjected to GBR irrigation.

\section{Discussion}

Controversy has existed on the effect of ultrasound from phacoemulsification on corneal endothelium. Emery and Patton (1974) found no endothelial damage from ultrasound, but they did not specify the amount of time the cornea was exposed, and Ito (1970) found no irreversible changes after 5 minutes of exposure. In contrast Polack and Sugar (1976) and Binder et al. (1976) have shown endothelial lesions and cell destruction in cats and rabbits following complete phacoemulsification procedures using 4 to 11 minutes of ultrasound. However, neither of these papers described endothelial cell loss following irrigation and ultrasound alone. Our results show that ultrasound in amounts commonly used during phacoemulsification can produce a wide spectrum of endothelial damage to human corneas.

Concern has been expressed over the possible deleterious effects of intraocular ultrasound. The recommended safe levels for ocular exposure to ultrasound have been obtained from studies of ocular damage following the application of ultrasound to the external surface of the cornea. Baum (1956) considered $0.25 \mathrm{~W} / \mathrm{cm}^{2} / 5$ min a safe level at which all damage was reversible. The transience of damage produced by stimulus intensities of this order has been verified by Aristarkhova and Nuritoinov (1974), who recorded a reversible increase in corneal permeability with $0.2 \mathrm{~W} / \mathrm{cm}^{2}$, and by Marmur and Plevinskis (1973), who showed transient increases, lasting only some hours, in both DNA and protein content in the corneal epithelium of the rabbit. Diagnostic ultrasound at intensities of $0.0337 \mathrm{~W} / \mathrm{cm}^{2}$ caused no damage when applied directly to the corneal endothelium for 4 hours (Ziskan et al., 1974). The calculated intensity emanating from the tip of the phacoemulsifier is 0.0034 $\mathrm{W} / \mathrm{cm}^{2}$, and this is well below the levels formerly considered safe (Kelman, 1967).

In the present study a spectrum of damage has been observed in response to any prolonged dose of ultrasound. This implies that either the radiation field is non-uniform at the endothelium, or that individual cells have different tolerances or damage thresholds to ultrasonic vibration. These suppositions are not mutually exclusive and probably both are involved in lesion formation. We consider the reaction sequence to be as follows: (1) Cytoplasmic disruption near the basement membrane; (2) cellular condensation and contraction of apical membranes; (3) rupture of apical membranes and cytoplasmic loss; (4) increase in peripheral involvement and cell loss; (5) gross endothelial sloughing.

The underlying mechanism in the primary production of damage is unclear. Moore et al. (1955) observed formation of spongy areas in deep stroma and suggested possible localised structural heating resulting from acoustic impedence differences between cornea and aqueous as a cause for cell damage. In our studies the basal concentration of disruptive effects is a consistent initial finding. This may indicate that the differences in elasticity of tissues at an interface-that is, cell membrane to cell membrane or Descemet's membrane to cell membrane-may cause unequal shear forces during vibration and thus result in damage. However, the distribution and nature of cellular damage supports the concept that these lesions could be caused by cavitation or simply a degassing of cytoplasmic water.

The condensation or shrinkage of cells is a common response to trauma and results in the opening of extracellular space. In most cases cells with a basement membrane break all other junctional complexes before that with their basement structures (Marshall and Fankhauser, 1972). If the shrinkage is sufficiently severe to result in apical rupture, then a constraint to lateral vibration is removed from adjacent cells and the lesion may grow in size. If the lesion becomes very large, the cohesion between cells at the edges is much reduced and sloughing may ensue.

The presence of air bubbles in the anterior chamber is a frequent occurrence during use of the ultrasound probe. Endothelial lesions resulting from the damaging effects of air within the anterior chamber have been observed with a specular microscope (Leibowitz et al., 1974), and the circulation of air 

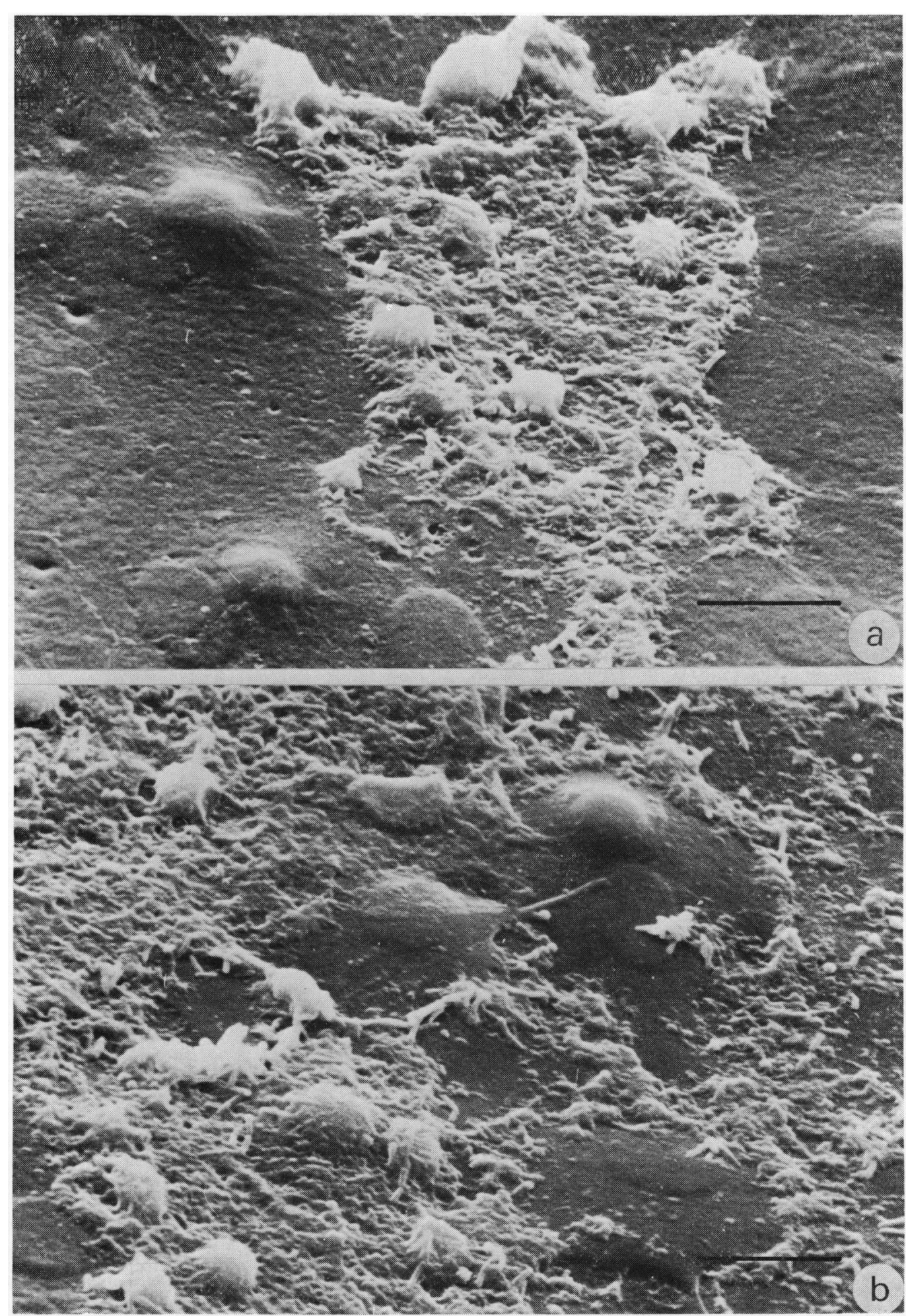

Fig. 5 Scanning electron micrographs of corneal endothelium in an advanced stage of Fuchs's endothelial dystrophy after 5 minutes' exposure to ultrasound. Damage was observed in all areas, but when lesions included a guttata cell loss was always apparent over the excresences of Descemet's membrane. Bar markers: $a=20 \mu \mathrm{m}, \mathrm{b}=20 \mu \mathrm{m}$ 
bubbles against the endothelium has been proposed as a mechanism for endothelial damage during phacoemulsification (Polack and Sugar, 1976). These bubbles arise from the degassing effect of ultrasound and form on the metal tip, from where they are released into the anterior chamber. They circulate in the currents of irrigation fluid, which are caused by the directional flow of the hole in the irrigation sleeve, until they are finally aspirated. In our experiments a comparable amount of air was allowed to enter and circulate in the anterior chamber of control eyes during irrigation and aspiration, and no changes in the appearance of the endothelium were observed.

The irrigating media used in the modern intraocular surgical devices have been implicated as a
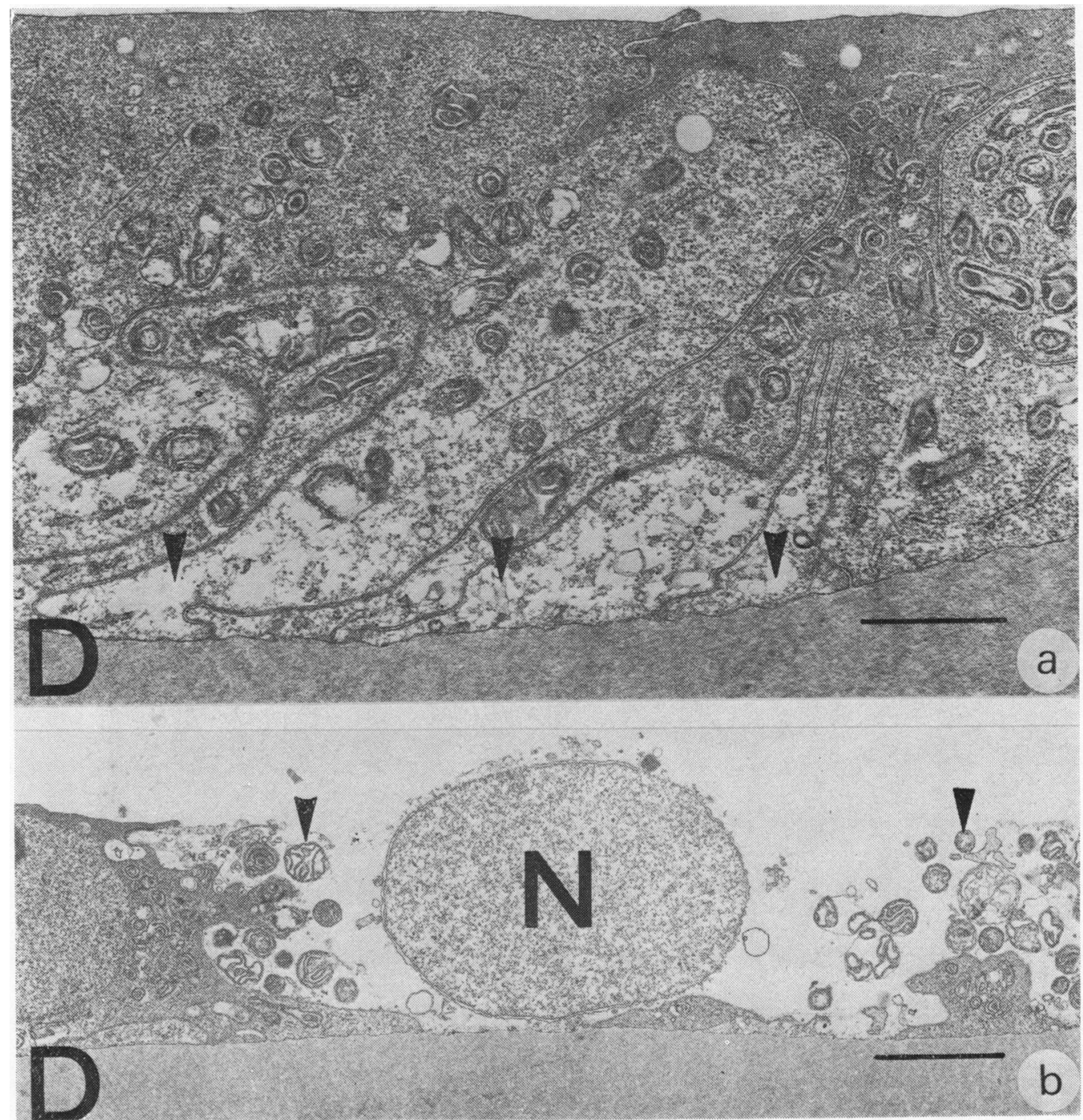

Fig. 6 Transmission electron micrographs of human corneal endothelium showing changes after 5 minutes' exposure to ultrasound. (a) Mild damage showing the vacuolation and disruption of cytoplasm (arrowed) adjacent to Descemet's membrane. In most cases organelles and membranes in this region appear relatively undamaged. D is Descemet's membrane. (b) A more severe lesion in which cellular disruption has occurred. The nucleus (N) is retained in the damage site even though the cell's boundary membrane has ruptured and most of the cytoplasmic contents are lost. Relatively normal but extracellular mitochondria (arrowed) are often found in association with the pseudopodia-like processes from adjacent cells. Bar markers: $\mathrm{a}=1 \mu \mathrm{m}, \mathrm{b}=2 \mu \mathrm{m}$ 
possible cause of endothelial damage (Edelhauser et al., 1975; McCarey et al., 1976). In an attempt to minimise endothelial damage GBR was used throughout the present study and no damage was produced in control eyes.
A normal cornea has been considered a prerequisite for phacoemulsification, and any endothelial abnormality is considered a contraindication, with Fuchs's endothelial dystrophy a prime example (Kelman, 1973). In our case of advanced human
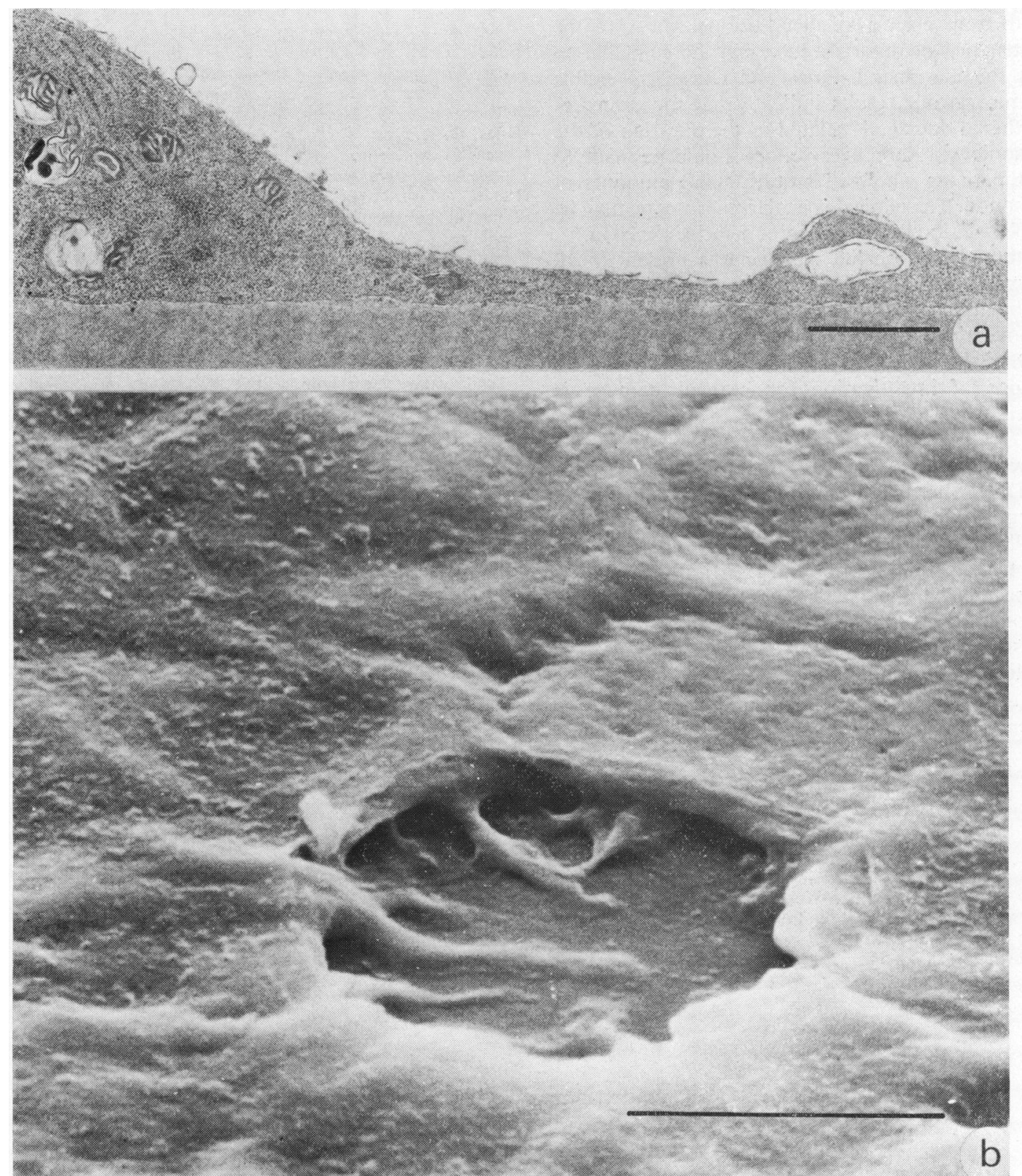

Fig. 7 (a) Transmission electron micrograph of a pseudopodia-like process illustrated in (b), showing the sparsity of organelles in these structures. (b) Scanning electron micrograph of a single cell lesion in the corneal endothelium of a rabbit produced by a 2-minute exposure to ultrasound. In both rabbit and human pseudopodia-like processes rapidly invade the damage site from adjacent cells. Bar markers: $\mathrm{a}=1 \mu \mathrm{m}, \mathrm{b}=20 \mu \mathrm{m}$ 
Fuchs's endothelial dystrophy subjected to ultrasound the damage did not appear to be greater in magnitude or extent than that seen in a normal cornea after ultrasound. However, cell loss generally occurred first over and around the excrescences on Descemet's membrane (Fig. 5). We therefore support Kelman's conclusions, as in a compromised endothelium even a small additional stress to the maintenance of deturgescence may be sufficient to upset the marginal balance and cause irreversible oedema. As our results indicate that the extent of endothelial damage is related to the duration of the ultrasonic exposure, every effort should be made to select patients who will require small amounts of ultrasound. The clinical specular microscope may be a useful aid in making this preoperative decision.

Although endothelial damage was present in all our experimental corneas, the extent of this damage may be no greater than that after cataract extraction by conventional techniques. Therefore a comparative study of the various cataract techniques by modern methods of investigation for corneal damage is needed.

We would like to thank Professor Barrie R. Jones and Dr E. Sherrard for guidance and helpful advice during this project. We are grateful to $\mathrm{Mr} \mathrm{P}$. L. Ansell, Miss E. Clarke, and Mr J. Haddington for their technical assistance, and to Miss R. Condliffe for secretarial help. The transmission electron microscope was provided by the Wellcome Trust and some financial support was provided by the Pocklington Trust.

\section{References}

Aristarkhova, A. A., and Nuritoinov, V. A. (1974). The effect of ultrasound on the corneal permeability. Vestnik oftal'mologii, 90 (3), 46-48.

Baum, G. (1956). The effect of ultrasonic radiation upon the eye and ocular adnexa. American Journal of Ophthalmology, 42, 696-706.

Binder, P. S., Sternberg, H., Wickham, M. G., and Worthen, D. M. (1976). Corneal endothelial damage associated with phacoemulsification. American Journal of Ophthalmology, 82 (1), 43-54.
Cleasby, G. W., Fung, W. E., and Webster, R. G. (1974). The lens fragmentation and aspiration procedures (phacoemulsification). American Journal of Ophthalmology, 77, 384-387.

Cleveland, P. H., and Schneider, C. W. (1969). A simple method of preserving ocular tissue for scanning electron microscopy. Vision Research, 9, 1401-1402.

Edelhauser, H. F., van Horn, D. L., Hyndiuk, R. A., and Schultz, R. O. (1975). Intraocular irrigating solutions. Archives of Ophthalmology, 93 (8), 648-657.

Emery, J. M., and Patton, D. (1974). Phacoemulsification. In Current Concepts in Cataract Surgery. Selected Proceedings of the Third Biennial Cataract Surgical Congress. C. V. Mosby: St. Louis.

Hiles, D. A., and Hurite, F. G. (1973). Results of the first year's experience with phacoemulsification. American Journal of Ophthalmology, 75, 473-477.

Ito, K. (1970). Experimental studies on clinical and pathological changes of neighbouring tissues of lens by ultrasonic vibrating tip for phacoemulsification. Pt. 1. Clinical and pathological changes using non-coated tip. Acta Societatis Ophthalmologicae Japonicae, 74, 557-566.

Kelman, C. D. (1967). Phacoemulsification and aspiration: a new technique of cataract removal. A preliminary report. American Journal of Ophthalmology, 64 (1), 23-35.

Kelman, C. D. (1973). Phacoemulsification and aspiration of senile cataracts: a comparative study with intracapsular extraction. Canadian Journal of Ophthalmology, 8, 24-32.

Kelman, C. D. (1974). Symposium: Phacoemulsification. Summary of personal experience. Transactions of the American Academy of Ophthalmology and Otolaryngology, 78, 35-38.

Leibowitz, H. M., Laing, R. A., and Sandstrom, M. (1974). Corneal Endothelium. The effect of air in the anterior chamber. Archives of Ophthalmology, 92, 227-230.

McCarey, B. E., Polack, F. M., and Marshall, W. (1976). The phacoemulsification procedure. I. The effect of intraocular irrigating solutions on the corneal endothelium. Investigative Ophthalmology, 15 (6), 449-457.

Marmur, R. K., and Plevinskis, V. P. (1973). Ultrasonic effect on nucleic acids and amino-groups of corneal proteins. Oftal'mologicheskii zhurnal, 28 (5), 387-391.

Marshall, J., and Fankhauser, F. (1972). The effect of light radiation on blood vessels and membranes. Transactions of the Ophthalmological Societies of the United Kingdom, 92, 469-478.

Moore, C. H., Herrick, J. F., and Martens, T. G. (1955). Some effects of ultrasonic energy on the rabbit eye. Archives of Ophthalmology, 54, 922-939.

Polack, F. M., and Sugar, A. (1976). The phacoemulsification procedure. II. Corneal endothelium changes. Investigative Ophthalmology, 15 (6), 458-469.

Ziskin, M. C., Romayananda, N., and Harris, K. (1974). Ophthalmologic effect of ultrasound at diagnostic intensities. Journal of Clinical Ultrasound, 2, 119-122. 